\title{
Permodelan Kurva Karakteristik Inverse Non- Standart Pada Rele Arus Lebih Dengan Metode Adaptive Neuro Fuzzy Inference System (Anfis)
}

\author{
Erhankana Ardiana P., Margo Pujiantara dan Ardyono Priyadi \\ Jurusan Teknik Elektro, Fakultas Teknologi Industri, Institut Teknologi Sepuluh Nopember (ITS) \\ Jl. Arief Rahman Hakim, Surabaya 60111 \\ E-mail: erhankana14@mhs.ee.its.ac.id, margo@ee.its.ac.id, priyadi@ee.its.ac.id
}

\begin{abstract}
Abstrak - Pada sistem kelistrikan terutama pada sistem proteksi kelistrikan dewasa ini sangat dibutuhkan sistem yang handal, sehingga perkembangan pada sistem proteksi sudah semakin maju dengan adanya penggunaan rele digital. Rele digital digunakan dengan mempertimbangkan kecepatan, keakuratan dan serta flexible dalam sistem koordinasi. Flexibilitas ini dimaksudkan bahwa rele digital dapat digunakan menjadi rele arus lebih (overcurrent relay) sesuai pembahasan tugas akhir ini dan dapat disetting menurut keinginan user sesuai karakteristik kurva OCR konvensional/standart (normal inverse, very inverse, long time inverse, extreme inverse) yang akan digunakan dalam koordinasi. Jenis kurva pada rele digital juga dapat disetting diluar rumus kurva konvensional/standart yang seperti sudah disebutkan sebelumnya, kurva diluar rumusan standart disebut kurva rele non-standart. Kurva rele nonstandart digunakan untuk memudahkan pengguna untuk menentukan waktu trip berdasarkan arus yang diinginkan dan sebagai solusi jika pada koordinasi proteksi mengalami kendala dalam koordinasi kurva rele. Pada tugas akhir ini akan dibahas bagaimana membuat atau memodelkan kurva karakteristik inverse overcurrent rele non-standart dengan menggunakan metode (Adaptive Neuro Fuzzy Inference System) atau biasa disebut metode pembelajaran ANFIS. Kurva non-standart didapatkan dengan pengambilan titik-titik data baru berupa arus dan waktu trip sesuai keinginan user. Data baru tersebut akan digabungkan dengan data lama sehingga menghasilkan data non-standart yang nantinya akan dilakukan pembelajaran dengan metode ANFIS untuk mendapatkan desain kurva nonstandart. Setelah didapatkan desain kurva non-standart akan dilakukan simulasi pada software Etap 12.6 untuk memastikan bahwa kurva non-standart sudah sesuai dengan koordinasi proteksi yang diinginkan dan dapat diaplikaikan pada software Etap 12.6.
\end{abstract}

Kata Kunci : rele digital, overcurrent rele, non-standart, inverse overcurrent rele, ANFIS.

\section{PENDAHULUAN}

$\mathrm{K}$ EHANDALAN suatu sistem kelistrikan merupakan suatu hal yang menjadi prioritas utama. Terutama pada sistem distribusi yang menjadi pemasok aliran daya menuju beban. Pentingnya menjaga kehandalan sistem distribusi guna mempertahankan kontinyuitas tenaga listrik menuju beban.

Salah satu cara dalam mempertahankan kehandalan ialah koordinasi sistem proteksi yang baik pada sistem kelistrikan tersebut. Banyaknya jenis rele yang digunakan pada sistem tentunya harus di-koordinasikan secara tepat agar mampu menanggulangi setiap gangguan yang terjadi tanpa kesalahan sedikitpun. Salah satunya metode koordinasi dengan karakteristik tripping non-standar, dimana rele non-standart ini dapat bermanfaat saat terdapat kurva berhimpitan atau saling cross atau berhimpitan sehingga menimbulkan trip CB yang bersamaan pada beberapa arus tertentu. Dalam tugas akhir ini akan dilakukan studi mengenai cara memodelkan kurva nonstandart menggunakan metode ANFIS. Mendesain kurva nonstandart pada tugas akhir ini menerapkan kemampuan belajar Adaptive Neuro Fuzzy Interference System (ANFIS). Laptop atau Personal Computer (PC) digunakan sebagai sarana untuk membuat interface pemodelan kurva non-standart serta untuk simulasi hasil dari permodelan kurva menggunakan metode ANFIS yang dimana didalan proses permodelan metode ANFIS dilakukan inisialisasi beserta learning hingga didapat hasil learning dan parameter hasil learning.

\section{HUBUNG SINGKAT, RELE ARUS LEBIH \& ANFIS}

\section{A. Jenis-jenis Gangguan}

Adanya gangguan pada sistem tenaga listrik menyebabkan terjadinya kenaikan arus yang sangat besar menuju ke titik gangguan, sehingga arus yang melewati peralatan juga akan sangat besar. Bila hal ini dibiarkan maka arus yang melewati peralatan dapat merusak peralatan karena diluar kapasitas yang diijinkan. Pada umumnya gangguan yang terjadi pada sistem adalah gangguan beban lebih (overload) dan gangguan hubung singkat (Short Circuit) ${ }^{[2]}$.

- Gangguan hubung singkat

Hubung singkat adalah terjadinya hubungan penghantar bertegangan atau penghantar tidak bertegangan yang memiliki beda potensial secara langsung, sehingga terjadi aliran arus yang tidak normal atau sangat besar. Gangguan hubung singkat ini dapat dibedakan menjadi 2 kategori, yaitu gangguan hubung singkat simetri dan asimetri ${ }^{[1]}$.

\section{B. Rele Arus lebih}

Pada dasarnya rele arus lebih berfungsi sebagai pengaman saat terjadi gangguan hubung singkat, selain itu dapat juga digunakan sebagai pengaman beban lebih (overload). Rele arus lebih merupakan suatu jenis rele yang bekerja berdasarkan besarnya arus masukan, dan apabila besarnya arus masukan melebihi suatu harga tertentu yang dapat diatur $\left(\mathrm{I}_{\mathrm{p}}\right)$ maka rele arus lebih bekerja. Dimana Ip merupakan arus kerja yang dinyatakan menurut gulungan sekunder dari trafo arus 
(CT). Bila suatu gangguan terjadi didalam daerah perlindungan rele, besarnya arus gangguan $\mathrm{I}_{\mathrm{f}}$ yang juga dinyatakan terhadap gulungan sekunder CT juga. Rele akan bekerja apabila memenuhi keadaan sebagai berikut ${ }^{[1]}$ :

$$
\begin{aligned}
& \text { If }>\text { Ip } \longrightarrow \text { rele bekerja, CB trip } \\
& \text { If }<\text { Ip } \longrightarrow \text { rele tidak bekerja }
\end{aligned}
$$

Rele arus lebih waktu invers memiliki waktu operasi yang berbanding terbalik dengan besar nya arus gangguan. Jadi, semakin besar arus gangguan maka rele akan bekerja dalam waktu yang semakin cepat ${ }^{[3]}$.

\section{Rele Karakteristik Tripping Non-Standart}

Dalam kasus tertentu di sistem tenaga industri, komplektivitas koordinasi proteksi meningkat dengan banyaknya rele yang akan dikoordinasikan.terkadang dengan kondisi banyaknya kurva yang dikoordinasikan salah satu kurva akan berhimpitan dengan kurva yang lainnya, sedangkan untuk koordinasi yang baik semua kurva harus mengikuti grading time yang sudah ditentukan. Kondisi tersebut mengharuskan sistem koordinasi tidak harus mengikuti rumusan kurva standart yang dimana akan sulit jika koordinasi melibatkan banyak kurva rele. Tanpa mengikuti rumusan kurva standart, cara yang memungkinkan untuk dilakukan dalam pengoordinasian sistem proteksi adalah dengan memodelkan kurva rele yang dapat disebut kurva nonstandart $^{[10]}$. Berikut gambaran dalam permodelan kurva rele non-standart :

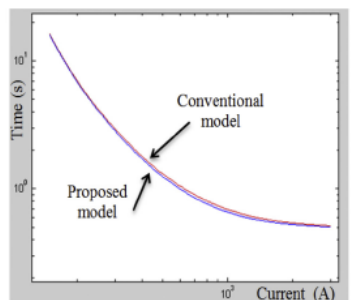

Gambar 1 Kurva rele standart dan kurva rele yang dikehendaki ${ }^{[10]}$

D. ANFIS

ANFIS (Adaptive Neuro Fuzzy Inference System atau Adaptive Network-based Fuzzy Inference System) adalah suatu metode yang dimana dalam melakukan penyetalan aturan digunakan algortima pembelajaran terhadap sekumpulan data.

\section{- Arsitektur ANFIS}

Misalkan input terdiri atas $Z_{1, t}$ dan $Z_{2, t}$ dan sebuah output $Z_{t}$ dengan aturan model sugeno orde 1 . Orde satu dipilih dengan pertimbangan kesederhanaan dan kemudahan perhitungan. Model sugeno orde satu dengan dua aturan fuzzy if-then adalah sebagai berikut:

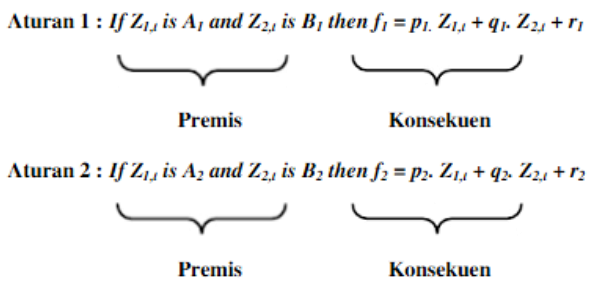

Gambar 2 Aturan arsitektur ANFIS
Dengan $A_{i}$ dan $B_{i}$ adalah nilai-nilai keanggotaan dan merupakan label linguistik (seperti "kecil" atau "besar"), $p_{i}, q_{i}$ dan $r_{i}$ adalah parameter konsekuen.
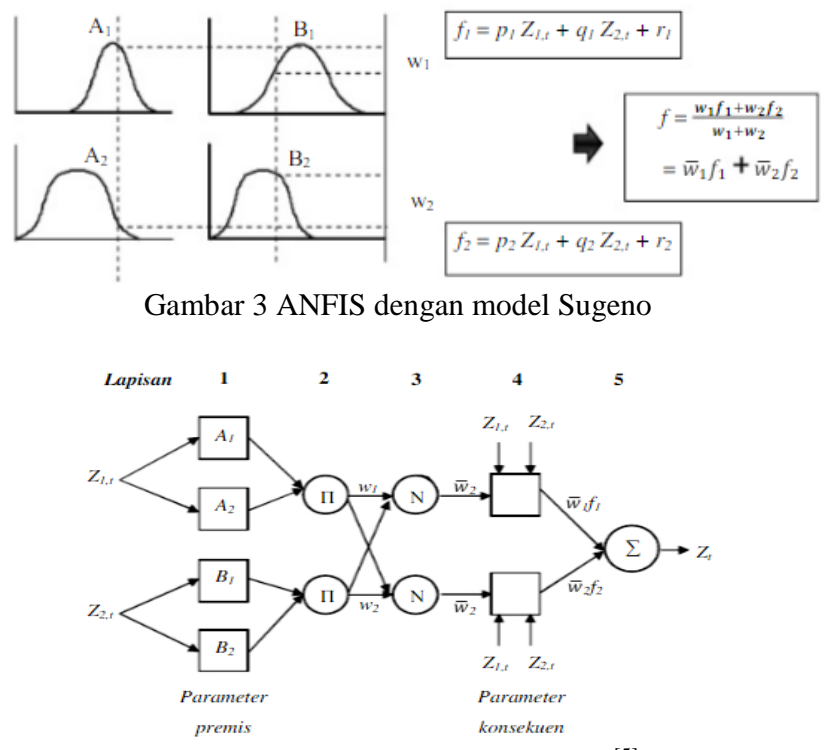

Gambar 4 Arsitektur jaringan ANFIS ${ }^{[5]}$

\section{Lapisan 1:}

Lapisan ini merupakan lapisan fuzzifikasi. Pada lapisan ini tiap neuron adaptif terhadap parameter suatu aktivasi. Output dari tiap neuron berupa derajat keanggotaan yang diberikan oleh fungsi keanggotaan input. Misalkan fungsi keanggotaan Generalized Bell diberikan sebagai :

$$
\mu(Z)=\frac{1}{1+\left|\frac{Z-c}{a}\right|^{2 b}}
$$

Dengan $\mathrm{Z}$ adalah input, dalam hal ini $\mathrm{Z}=\left\{Z_{1, t}, Z_{2, t}\right\}$ dan $\{\mathrm{a}$. $b$, dan $c\}$ adalah parameter-parameter, biasanya $b=1$. Jika nilai parameter-parameter ini berubah,maka bentuk kurva yang terjadi akan ikut berubah. Parameter-parameter ini biasanya disebut dengan nama parameter premis.

\section{Lapisan 2:}

Lapisan ini berupa neuron tetap (diberi symbol П) merupakan hasil kali dari semua masukan, sebagai berikut :

$$
w_{1}=\mu_{A i} \cdot \mu_{B i}
$$

Biasanya digunakan operator AND. Hasil perhitungan ini disebut firing strength dari sebuah aturan. Tiap neuron mempresentaikan aturan ke-i.

\section{Lapisan 3:}

Tiap neuron pada lapisan ini berupa neuron tetap (diberi symbol N). Merupakan hasil perhitungan rasio dari firing strength ke-I $\left(\mathrm{w}_{\mathrm{i}}\right)$ terhadap jumlah dari keseluruhan firing strength pada lapisan kedua, sebagai berikut :

$$
w_{1}=\frac{w_{1}}{w_{1}+w_{2}}, i=1,2
$$

Hasil perhitungan ini disebut normalized firing strength. Lapisan 4:

Lapisan ini berupa neuron yang merupakan neuron adaptif terhadap suatu output, sebagai berikut : 


$$
w_{i} f_{i}=w_{i}\left(p_{i} Z_{1, t}+q_{i} Z_{2, t}+r_{i}\right)
$$

Dengan $w_{i}$ adalah normalized firing strength pada lapisan ketiga dan $p_{i}, q_{i}$ dan $r_{i}$ adalah parameter-parameter pada neuron tersebut. Parameter-parameter ini biasa disebut parameter konsekuen.

\section{Lapisan 5:}

Lapisan ini berupa neuron tunggal (diberi symbol $\Sigma$ ) merupakan hasil penjumlahan seluruh output dari lapisan keempat, sebagai berikut ${ }^{[5]}$ :

$$
\sum_{i} w_{i} f_{i}=\frac{\Sigma_{i} w_{i} f_{i}}{\Sigma_{i} w_{i}}
$$

\section{PERANCANGAN SOFTWARE}

\section{A. Perancangan Software}

Dalam perancangan software yang menggunakan Matlab 2013 dengan interface GUI bertujuan sebagai simulasi hasil dari pembelajaran metode ANFIS dan hasil permodelan kurva Non-standart. Sebelum melakukan perancangan software simulasi terlebih dahulu melihat data-data rele yang terdapat pada single line diagram PT.HESS Indonesia.

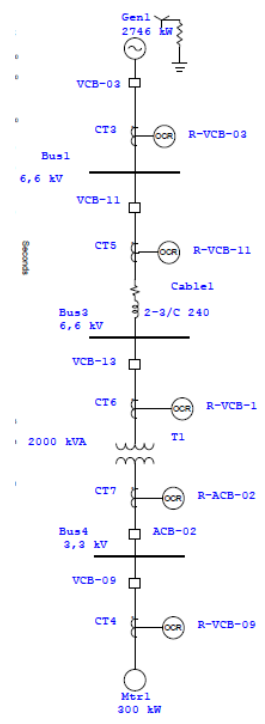

Gambar 5 Single line diagram PT.HESS Indonesia

Untuk single line diagram dari PT. HESS diambil beberapa bagian yang tipikal agar memudahkan dalam pengamatan dan menganalisa bentuk kurva koordinasi rele. Dalam kasus kali ini digunakan kurva dari rele R-VCB-9 dan R-ACB-02 berada dalam kondisi berhimpitan seperti gambar dibawah ini :

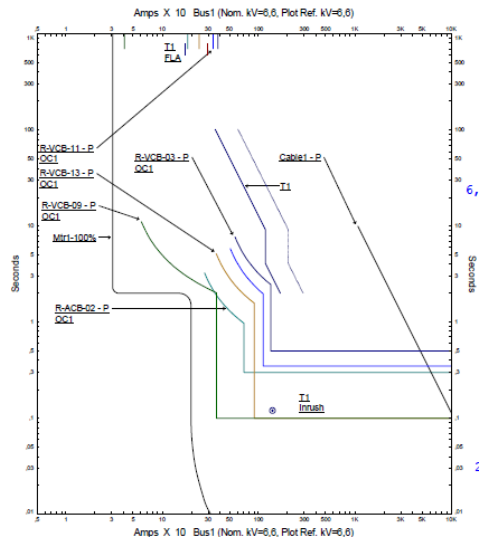

Gambar 6 Kurva R-VCB9 dan R-ACB02 berhimpitan

Dari kasus tersebut diperlukan permodelan kurva baru sebagai solusi agar antar kurva tidak bersinggungan lagi. Permodelan kurva dilakukan dengan mengambil beberapa data baru dimana akan membentuk suatu kurva baru yang sudah tidak bersinggungan lagi dengan kurva lainnya. Berikut merupakan contoh dari pengambilan data baru :

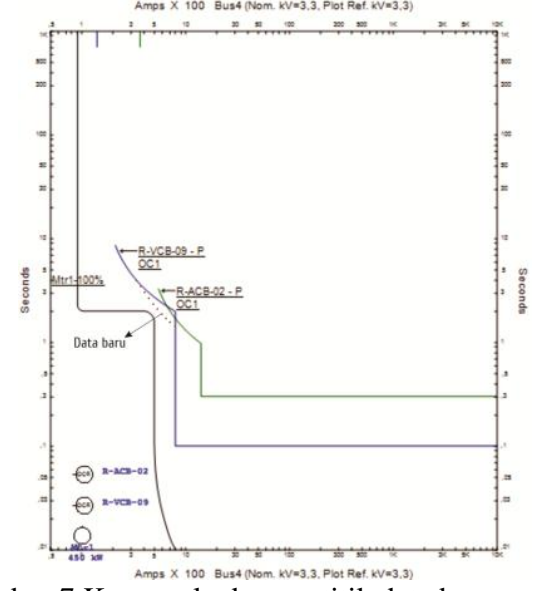

Gambar 7 Kurva rele dengan titik data baru

Dengan menggunakan titik baru seperti diperlihatkan titik "data baru" pada gambar diatas didapatkan kurva rele yang baru atau sudah non-standart dengan hasil kurva tidak bersinggungan dan dapat bekerja sesuai dengan rencana koordinasi proteksi.

\section{- Perancangan Interface GUI Matlab 2013}

Dalam perancangan interface tugas akhir ini bertujuan agar user dapat membuktikan secara langsung hasil dari pembelajaran metode yang digunakan dalam permodelan kurva rele sudah mencapai hasil yang diinginkan atau belum. Berikut merupakan gambar dari interface GUI yang dibuat :

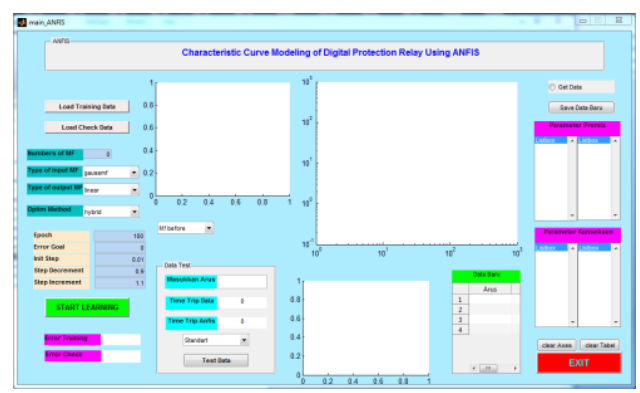

Gambar 8 Interface GUI Matlab 2013 


\section{HASIL PENGUJIAN DAN SIMULASI}

\section{A. Pengujian Data Kurva Non-Standart}

Pada pecobaan kali ini akan dilakukan terlebih dahulu pembuatan data Non-standart dengan menggabungkan data pada rele yang sudah ada dengan data-data baru yang didapatkan. Penggabungan data dengan melihat batas dimana nilai pengambilan data baru akan menggantikan data lama, semisalkan data baru dimulai pada nilai arus $130,91 \mathrm{~A}$ seperti maka pada data lama nilai dibawah $125 \mathrm{~A}$ akan digantikan dengan data baru. Berikut ini cara penggabungan data kurva standart dan data baru :

Tabel 1 Data kurva Standart Inverse

\begin{tabular}{rrrrrrrr}
\hline \hline $\begin{array}{l}\text { Arus } \\
\text { (A) }\end{array}$ & Trip (s) & $\begin{array}{l}\text { Arus } \\
\text { (A) }\end{array}$ & $\begin{array}{l}\text { Trip } \\
\text { (s) }\end{array}$ & $\begin{array}{l}\text { Arus } \\
\text { (A) }\end{array}$ & $\begin{array}{l}\text { Trip } \\
\text { (s) }\end{array}$ & $\begin{array}{l}\text { Arus } \\
\text { (A) }\end{array}$ & $\begin{array}{l}\text { Trip } \\
\text { (s) }\end{array}$ \\
\hline 95 & 28,494 & 285 & 3,571 & 485 & 2,497 & 685 & 2,086 \\
105 & 17,488 & 295 & 3,475 & 495 & 2,468 & 695 & 2,072 \\
115 & 12,937 & 305 & 3,386 & 505 & 2,441 & 705 & 2,058 \\
125 & 10,442 & 315 & 3,305 & 515 & 2,415 & 715 & 2,044 \\
135 & 8,862 & 325 & 3,230 & 525 & 2,389 & 725 & 2,031 \\
145 & 7,769 & 335 & 3,160 & 535 & 2,365 & 735 & 2,018 \\
155 & 6,966 & 345 & 3,095 & 545 & 2,342 & & \\
165 & 6,350 & 355 & 3,034 & 555 & 2,319 & & \\
175 & 5,861 & 365 & 2,977 & 565 & 2,297 & & \\
185 & 5,464 & 375 & 2,924 & 575 & 2,276 & & \\
195 & 5,134 & 385 & 2,874 & 585 & 2,256 & & \\
205 & 4,855 & 395 & 2,826 & 595 & 2,237 & & \\
215 & 4,616 & 405 & 2,782 & 605 & 2,218 & & \\
225 & 4,408 & 415 & 2,740 & 615 & 2,199 & & \\
235 & 4,226 & 425 & 2,700 & 625 & 2,182 & & \\
245 & 4,066 & 435 & 2,662 & 635 & 2,164 & & \\
255 & 3,922 & 445 & 2,626 & 645 & 2,148 & & \\
265 & 3,793 & 455 & 2,591 & 655 & 2,132 & & \\
275 & 3,677 & 465 & 2,558 & 665 & 2,116 & & \\
& & 475 & 2,527 & 675 & 2,101 & & \\
\hline \hline
\end{tabular}

Berikut merupakan contoh data baru yang didapatkan sebanyak 10 data :

Tabel 2

Data Baru

\begin{tabular}{rr}
\hline \multicolumn{2}{c}{ Data Baru } \\
\hline \hline Arus (A) & \multicolumn{1}{c}{ Trip (s) } \\
130,9157 & 9,019291 \\
152,7017 & 5,968457 \\
169,2046 & 5,011872 \\
192,3635 & 4,012807 \\
242,3266 & 3,01516 \\
301,376 & 2,53191 \\
394,5484 & 2,092617 \\
497,0257 & 1,872465 \\
602,4823 & 1,757226 \\
704,3 & 1,74 \\
\hline \hline
\end{tabular}

Setelah didapatkan data baru seperti tampak pada tabel, dengan melihat data pertama pada nilai 130,9157A maka pada data kurva standart pergantian atau penggabungan dimulai pada angka $125 \mathrm{~A}$ sehingga pada nilai arus $135 \mathrm{~A}$ sampai 735 A akan diganti dengan nilai data baru yang dimulai pada nilai 130,9157A sampai 704,3A. Hasil dari penggabungan data dapat dilihat pada tabel sebagai berikut :

\begin{tabular}{rr}
\multicolumn{2}{c}{ Tabel 3 Data non-standart } \\
\hline \hline Arus (A) & \multicolumn{1}{c}{ Trip (s) } \\
\hline 95 & 28,494 \\
105 & 17,488 \\
\hline
\end{tabular}

\begin{tabular}{rr}
\hline \hline 115 & 12,937 \\
125 & 10,442 \\
130,9157 & 9,019291 \\
152,7017 & 5,968457 \\
\hline \hline
\end{tabular}

Lanjutan Tabel 3 Data non-standart

\begin{tabular}{rr}
\hline \multicolumn{1}{c}{ Arus (A) } & \multicolumn{1}{c}{ Trip (s) } \\
\hline 169,2046 & 5,011872 \\
192,3635 & 4,012807 \\
242,3266 & 3,01516 \\
301,376 & 2,53191 \\
394,5484 & 2,092617 \\
497,0257 & 1,872465 \\
602,4823 & 1,757226 \\
704,3 & 1,74 \\
\hline \hline
\end{tabular}

\section{B. Pengujian Learning ANFIS data non-standart}

Percobaan ini dilakukan dengan jumlah 14 data yang ditraining dan jumlah MF (Membership Function) yang ditentukan sebesar $10 \mathrm{MF}$ dan jumlah iterasi sebanyak 100 kali didapatkan hasil output ANFIS sudah memenuhi target dengan MSE (mean squared error) sebesar 0,739 dan hasil kurva yang didapatkan adalah kurva non-standart. Berikut tampilan plot kurva pada interface GUI :

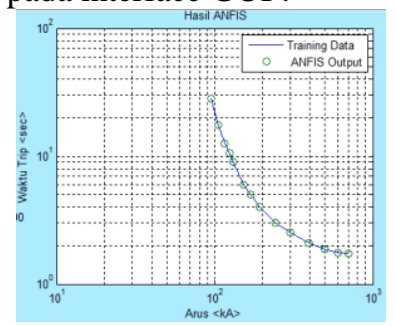

Gambar 9 Tampilan kurva non-standart pada kolot plot interface GUI

Pada kurva ditunjukkan learning ANFIS sudah mencapai target mengikuti kurva data non-standart yang ditunjukkan lingkaran hijau merupakan output learning ANFIS dan garis biru merupakan kurva non-standart yang akan dicapai. Berikut ini tabel error trip antara hasil ANFIS dan data target :

Tabel 4

Hasil error trip ANFIS berbanding trip data non-standart

\begin{tabular}{rrll}
\hline \hline Arus (A) & \multicolumn{1}{c}{ Trip N- } & Trip ANFIS & $\begin{array}{l}\text { Error } \\
(\mathbf{\%})\end{array}$ \\
\hline 95 & 28,494 & 27,83509103 & 2,367548 \\
105 & 17,488 & 18,79170054 & 6,940292 \\
115 & 12,937 & 12,58335434 & 2,807554 \\
125 & 10,442 & 9,765716843 & 6,922094 \\
130,9157 & 9,019291 & 9,222980113 & 2,208492 \\
152,7017 & 5,968457 & 6,393148057 & 6,64291 \\
169,2046 & 5,011872 & 4,728081393 & 6,002243 \\
192,3635 & 4,012807 & 4,051045991 & 0,943928 \\
242,3266 & 3,01516 & 3,014955748 & 0,00677 \\
301,376 & 2,53191 & 2,531820115 & 0,003553 \\
394,5484 & 2,092617 & 2,10216083 & 0,454022 \\
497,0257 & 1,872465 & 1,879449364 & 0,371598 \\
602,4823 & 1,757226 & 1,761483658 & 0,241717 \\
704,3 & 1,74 & 1,739353414 & 0,037174 \\
\hline \hline
\end{tabular}




\section{- Pengujian keakuratan dengan mengganti jumlah MF (Membership Function)}

Pengujian kali ini dilakukan untuk membuktikan keakuratan learning ANFIS untuk permodelan kurva data non-standart dengan mengubah-ubah nilai membership function (MF). Percobaan pertama dilakukan pada nilai membership function $(M F)=3$ dan dengan nilai epoch konstan 100, berikut hasil plot learning ANFIS pada GUI :

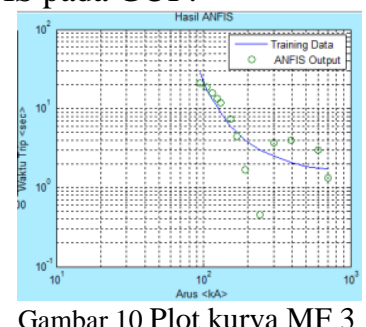

Dengan perngujian nilai $\mathrm{MF}=3$, hasil learning ANFIS yang ditunjukkan lingkaran warna hijau masih jauh untuk memenuhi target data sesuai dengan kurva data target yang ditampilkan oleh garis warna biru dan mempunyai rata-rata error sebesar $139,43 \%$. Berikutnya percobaan dengan $\mathrm{MF}=5$ dan berikut ini hasil plot pada GUI :

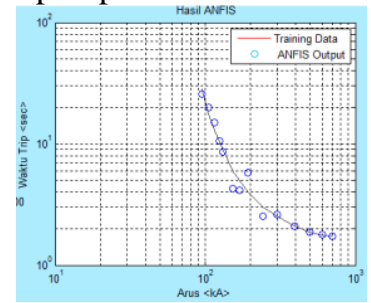

Gambar 11 Plot kurva MF 5

Penambahan nilai MF hasil learning ANFIS mulai mendekati target, namun hasil learning ANFIS masih belum mencapai target data non-standart dengan adanya error dibeberapa titik hasil learning ANFIS dengan nilai rata-rata error semakin kecil sebesar $11,26 \%$. Selanjutnya dilakukan pengujian dengan jumlah $\mathrm{MF}=10$, berikut hasil plot pada GUI :

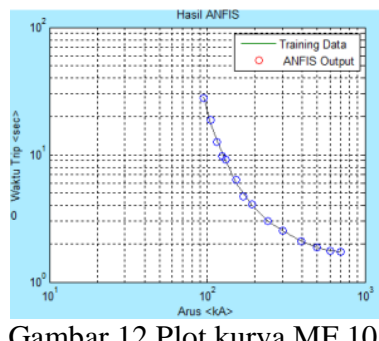

Pada gambar menunjukkan dengan penambahan nilai MF hasil learning ANFIS sudah mencapai target, meskipun hasil learning ANFIS masih mempunyai error dengan nilai yang sangat kecil dan nilai rata-rata error sebesar 2,56\%. Dengan penambahan nilai MF mulai dari 3, 5 sampai 10 nilai error yang dihasilkan semakin kecil, bahkan pada $\mathrm{MF}=10$ learning ANFIS sudah mencapai target dengan nilai error yang sangat kecil.

\section{- Pengaplikasian Kurva Pada Software Etap 12.6}

Sesudah didapatkan data non-standart dan telah dilakukan pengujian learning ANFIS pada interface GUI, akan dilakukan pengaplikasian atau percobaan kurva pada software Etap 12.6 untuk melihat apakah kurva non-standart sudah memenuhi syarat tidak terjadi bersinggungan lagi antar kurva rele dan memudahkan analisa hasil kurva non-standart. Berikut gambar kurva sebelum dilakukan permodelan non-standart :

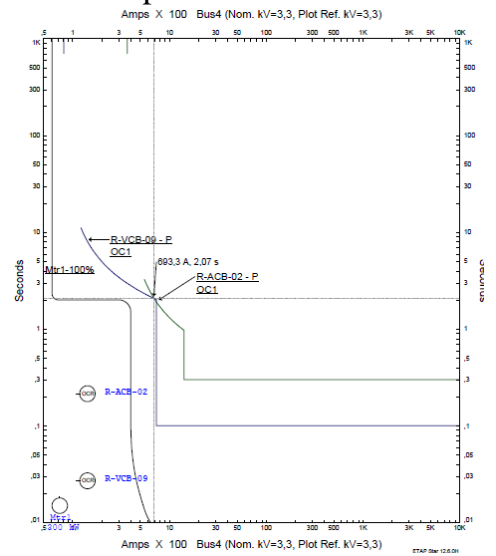

Gambar 13 Kurva masih saling bersinggungan

Gambar diatas saat kondisi kurva masih bersinggungan antara kurva rele R-VCB-9 dan R-ACB-02. Kedua rele akan mentripkan CB pada waktu 2,07s saat arus sebesar 693,3 A. Dari kondisi tersebut akan permodelan kurva non-standart pada kurva rele R-VCB-9 agar koordinasi proteki dapat berjalan dengan baik. Berikut ini menunjukkan gambar kurva non-standart yang sudah diplot pada software Etap 12.6 :

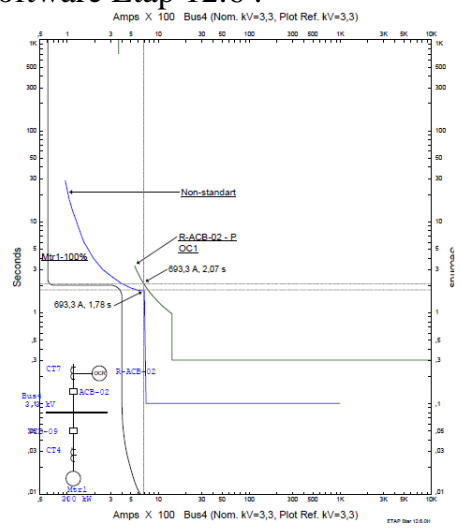

Gambar 14 Kurva non-standart pada tampilan star Etap 12.6

Gambar diatas menunjukkan untuk permodelan kurva nonstandart rele R-VCB -9 berhasil dan tidak bersinggungan lagi dengan kurva lainnya atau dalam kasus ini dengan kurva rele R-ACB-02. Pada gambar menunjukkan pada aat arus 693,3 A kurva rele R-VCB-9 mentripkan CB dengan waktu 1,78 S sedangkan untuk kurva R-ACB-02 mentripkan CB dengan waktu 2,07.

Berikut hasil error pada Etap dan data non-standart : Tabel 5

Error perbandingan hasil Etap dan data non-standart

\begin{tabular}{|c|c|c|c|}
\hline Arus (A) & $\begin{array}{l}\text { Trip ANFIS } \\
\text { (s) }\end{array}$ & $\begin{array}{l}\text { Trip } \\
\text { Etap(s) } \\
\end{array}$ & Error (\%) \\
\hline 95 & 27,835091 & 28,5 & 2,3887437 \\
\hline 105 & 18,791701 & 17,5 & 6,873782 \\
\hline 115 & 12,583354 & 13 & 3,3110858 \\
\hline 125 & 9,7657168 & 10,4 & 6,4949984 \\
\hline 130,91567 & 9,2229801 & 9,03 & 2,0923835 \\
\hline 152,70175 & 6,3931481 & 5,93 & 7,2444444 \\
\hline 169,20464 & 4,7280814 & 5,01 & 5,9626428 \\
\hline
\end{tabular}




\begin{tabular}{rrrr}
\hline \hline 192,36345 & 4,051046 & 4,01 & 1,0132196 \\
242,32661 & 3,0149557 & 3,01 & 0,1643722 \\
301,37598 & 2,5318201 & 2,53 & 0,0718896 \\
394,54839 & 2,1021608 & 2,09 & 0,5784919 \\
497,02568 & 1,8794494 & 1,86 & 1,0348437 \\
602,4823 & 1,7614837 & 1,76 & 0,0842278 \\
704,3 & 1,7393534 & 1,74 & 0,0371739 \\
\hline \hline
\end{tabular}

Dari error yang didapatkan hasil plot kurva pada Etap sudah mendekati target, dengan begitu kurva non-standart dapat diaplikasikan untuk simulasi pada sofware Etap dengan kasus jika koordinasi rele mengalami persinggungan antar rele dan menggunakan beberapa cara untuk mengatasi persinggungan tersebut tidak berhasil.

\section{PENUTUP}

Berdasarkan hasil simulasi dan analisis, maka disimpulkan sebagai berikut :

1. Pemodelan kurva karakteristik inverse maupun kurva karakteristik non-standart dapat dilakukan dengan metode pembelajaran ANFIS.

2. Semakin besar nilai MF maka tingkat keakuratan semakin bagus, pada pengujian ini MF dengan tingkat keakuratan paling bagus adalah $\mathrm{MF}=10$ dengan jumlah data sebanyak 14 data dan rata-rata error 2,56\% (masih dibawah 5\%)

3. Hasil dari learning ANFIS berupa kurva baru dapat diaplikasikan pada software Etap 12.6 dengan hasil kurva R-VCB 9 tidak berhimpitan dengan kurva R-ACB 02 dengan waktu trip 2,07 s untuk R-ACB 02 dan waktu trip CB R-VCB 9 sebesar 1,78 s pada arus 693,3 A.

4. Pengaplikasian kurva non-standart dengan jumlah 14 data pada software Etap 12.6 didapatkan rata-rata error sebesar $0,21 \%$.

\section{DAFTAR PUSTAKA}

[1] Ir R.Wahyudi. "Diktat Kuliah Pengaman Sistem Tenaga Listrik", Jurusan Teknik Elektro, Institut Teknologi Sepuluh Nopember,Surabaya.

[2] Soeprijanto, Adi "Kestabilan Sistem Tenaga Listrik, Diktat Kuliah Analisis Sistem Tenaga Listrik 2", Teknik Elektro Fakultas Teknologi Industri, Institut Teknologi Sepuluh Nopember Surabaya

[3] Datasheet Overcurrent Protection Relays", CKR Series.

[4] Warsito, B. "Kapita Selekta Statistika Neural Network". BP Undip Semarang, 2009.

[5] Sri Kusumadewi, Sri Hartati "Neuro - Fuzzy Integrasi Sistem Fuzzy dan Jaringan Syaraf". GRAHA ILMU, Yogyakarta, 2006.

[6] Jang, J.-S. R. and Sun, C.-T.: Neuro-fuzzy and soft computing: a computational approach to learning and machine intelligence, PrenticeHall, Inc., Upper Saddle River, NJ, USA, 1997.

[7] J.S.R. Jang "ANFIS: Adaptive Network Based Fuzzy Inference Systems", IEEE Trans, Syst. Man Cybernet. vol 23, No 3, pp. 665$685,1993$.

[8] Rachman Halim, Desain Kurva Konvensional Menggunakan Anfis Pada Digital Protection Relay, Teknik Elektro, Fakultas Industri , ITS, Surabaya, 2015.

[9] Anang Tjahjono, Ardyono Priyadi, Margo Pujiantara and Mauridhi Hery Purnomo, Overcurrent Relay Curve Modeling Using Adaptive Neuro Fuzzy Inference System, ITS, Surabaya, 2014.

[10] O. Arreola Soria*, A. Conde Enríquez, L.A. Trujillo Guajardo, Overcurrent relay with unconventional curves and its application in industrial power systems, Universidad Autónoma de Nuevo León, Mexico, 2014. 